The Journal of Bone E Joint Surgery
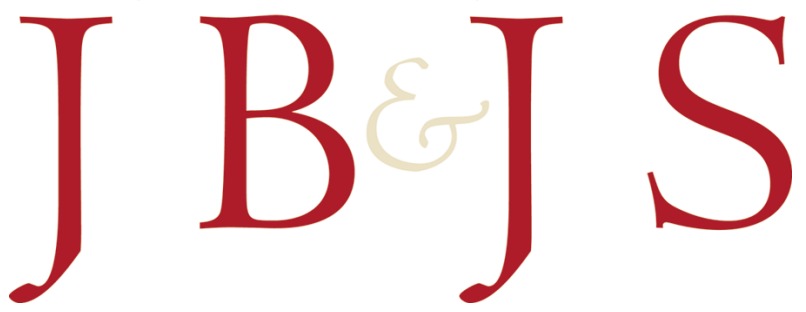

This is an enhanced PDF from The Journal of Bone and Joint Surgery

The PDF of the article you requested follows this cover page.

\title{
Interlocking Contoured Intramedullary Nail Fixation for Selected Diaphyseal Fractures of the Forearm in Adults
}

Young Ho Lee, Sang Ki Lee, Moon Sang Chung, Goo Hyun Baek, Hyun Sik Gong and Kyung Hwan Kim J Bone Joint Surg Am. 2008;90:1891-1898. doi:10.2106/JBJS.G.01636

This information is current as of December 23, 2009

Reprints and Permissions

Publisher Information
Click here to order reprints or request permission to use material from this article, or locate the article citation on jbjs.org and click on the [Reprints and Permissions] link.

The Journal of Bone and Joint Surgery

20 Pickering Street, Needham, MA 02492-3157

www.jbjs.org 


\title{
Interlocking Contoured Intramedullary Nail Fixation for Selected Diaphyseal Fractures of the Forearm in Adults
}

\author{
By Young Ho Lee, MD, Sang Ki Lee, MD, Moon Sang Chung, MD, Goo Hyun Baek, MD, \\ Hyun Sik Gong, MD, and Kyung Hwan Kim, MD \\ Investigation performed at the Department of Orthopedic Surgery, Eulji University College of Medicine, \\ Daejeon, and Seoul National University College of Medicine, Seoul, South Korea
}

\begin{abstract}
Background: Plate osteosynthesis is the most commonly used technique for the treatment of diaphyseal forearm fractures in adults. However, application of a plate can disrupt the periosteal blood supply and necessitates skin incisions that may be unsightly, and there is a risk of refracture if the implant is removed. The purpose of this study was to assess the early results of the use of a contoured interlocking intramedullary nail to stabilize displaced diaphyseal fractures of the forearm.
\end{abstract}

Methods: Between January 2004 and July 2006, a total of thirty-eight interlocking intramedullary nails were inserted into the forearms of twenty-seven adults. Eighteen nails were used in the radius and twenty were used in the ulna to stabilize a diaphyseal fracture. The mean follow-up period was seventeen months. Functional outcomes were assessed with use of the Grace and Eversmann rating system, and patient-rated outcomes were assessed by completion of the Disabilities of the Arm, Shoulder and Hand (DASH) questionnaire.

Results: The average time to fracture union was fourteen weeks. There was one nonunion of an open comminuted fracture of the middle third of the ulna. There were no deep infections or radioulnar synostoses. According to the Grace and Eversmann rating system, twenty-two patients (81\%) had an excellent result; three (11\%), a good result; and two (7\%), an acceptable result. The DASH scores averaged 15 points (range, 5 to 61 points).

Conclusions: Our experience indicates that the advantages of an interlocking intramedullary nail system for the radius and ulna are that it is technically straightforward, it allows a high rate of osseous consolidation, and it requires less surgical exposure and operative time than does plate osteosynthesis. We suggest that the interlocking intramedullary nail system be considered as an alternative to plate osteosynthesis for selected diaphyseal fractures of the forearm in adults.

Level of Evidence: Therapeutic Level IV. See Instructions to Authors for a complete description of levels of evidence.

$\mathrm{F}$ ractures of the radius or ulna should be stabilized in order to ensure axial and rotational alignment ${ }^{1}$, and plate osteosynthesis is the procedure of choice for the treatment of forearm fractures. However, although this technique usually results in adequate reduction and satisfactory healing, it has been criticized because periosteal stripping may increase the probability of delayed fracture union ${ }^{2,3}$. A $2.3 \%$ to $4 \%$ rate of nonunion ${ }^{4,5}$, a $1.9 \%$ to $30.4 \%$ rate of refracture ${ }^{6-10}$, and a $0.8 \%$ to $2.3 \%$ rate of infection ${ }^{11,12}$ have been reported as complications of plate fixation of forearm fractures. In addition, plate fixation can disrupt the blood supply and inhibit periosteal revascularization. In an effort to circumvent these problems, intramedullary nailing has been proposed as an alternative method for stabilizing and maintaining the reduction of forearm fractures ${ }^{13,14}$. This technique is commonly used for femoral fixation and, increasingly, for fractures of the tibia and humerus ${ }^{15-17}$. However, intramedullary nailing has not been widely used for fixation of forearm fractures because of its limited indications, reportedly high rates of nonunion, and need for additional immobilization ${ }^{18}$. Recently, a new type of

Disclosure: The authors did not receive any outside funding or grants in support of their research for or preparation of this work. Neither they nor a member of their immediate families received payments or other benefits or a commitment or agreement to provide such benefits from a commercial entity. No commercial entity paid or directed, or agreed to pay or direct, any benefits to any research fund, foundation, division, center, clinical practice, or other charitable or nonprofit organization with which the authors, or a member of their immediate families, are affiliated or associated. 
The Journal of Bone \& Joint Surgery • JBjS. Org Volume 90-A • Number $9 \cdot$ September 2008

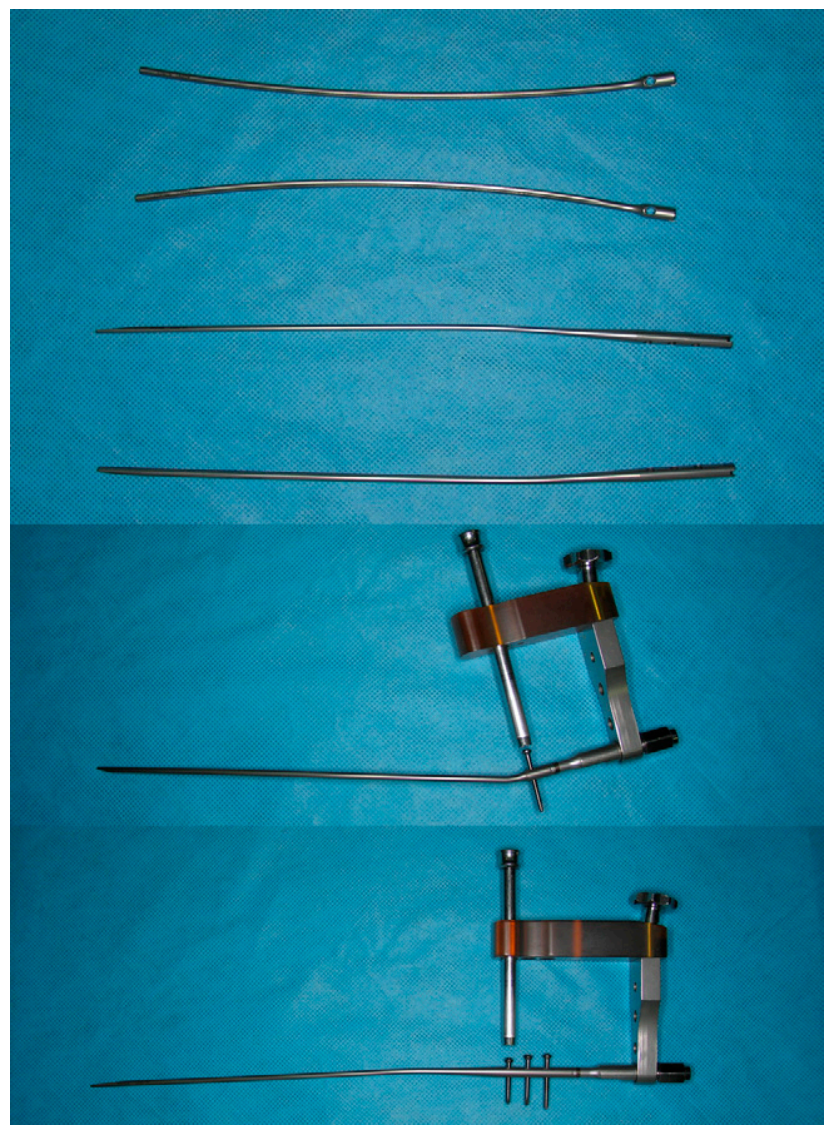

Fig. 1

Photographs of the interlocking contoured intramedullary nails for the forearm. The nails for the radius (top part of the image) are curved to facilitate easy insertion, and the distal portion is wide with a hole that can accept an interlocking screw. The nails for the ulna (upper-middle part of the image) are prebent $10^{\circ}$ for three-point fixation, and the proximal portion is wide with three holes through which interlocking screws can be inserted. Interlocking screws are inserted from a dorsal to volar direction in the distal part of the radius (lower-middle part of the image) and from lateral to medial in the proximal part of the ulna (bottom part of the image).

implant that is precontoured to the shape of the bone and is fluted to enhance rotational fracture control was introduced. The purpose of this study was to evaluate the suitability of this intramedullary nail system for the treatment of selected radial and/or ulnar fractures.

\section{Materials and Methods}

ur institutional review board granted permission for this study, and all patients who had been treated with the procedure under study were available for review. This retrospective study was performed from January 2004 to July 2006 and involved thirty-eight nails used in twenty-seven forearms. (A total of sixty-two fractures in forty-five forearms occurred between January 2004 and July 2006, and other surgical fixation techniques were used in the eighteen forearms [twentyfour fractures] that were not treated with the intramedullary
Interlocking Contoured Intramedullary Nail FiXation for Diaphyseal Forearm Fractures in Adults

nail.) Eighteen radial nails and twenty ulnar nails were used. In sixteen patients, only one bone was fractured (the radius in seven and the ulna in nine), whereas both forearm bones were fractured in eleven patients. All fractures were stabilized with the interlocking intramedullary nail system for the radius and ulna (Acumed, Hillsboro, Oregon).

The inclusion criteria were a simple diaphyseal fracture; a grade-I, II, or IIIA ${ }^{19,20}$ open fracture; a closed fracture with poor overlying skin and severe swelling; a segmental fracture; or a floating elbow. The exclusion criteria were a Monteggia fracture, a Galeazzi fracture, osteopenic bone and comminution, and a segmental comminuted fracture (when precise preservation of length was required).

\section{Specifics of Implant Design}

These solid titanium-alloy nails have unique features that are designed to rotationally stabilize a variety of fracture types. Each fluted nail is designed to be flexible enough to be inserted through a small incision with little or no reaming. A targeted interlocking screw, combined with a paddle-blade-tip design, locks and rotationally secures bone segments (Acumed) (Fig. 1). The nail for the radius is anatomically curved to facilitate insertion, and the nail for the ulna is prebent $10^{\circ}$ to achieve three-point fixation. Side-specific prebent nails are used for the left and right forearms. The nails are available in diameters of 3.0 and $3.6 \mathrm{~mm}$ and have lengths that range from 190 to 270 $\mathrm{mm}$ (190 to $230 \mathrm{~mm}$ for the radius and 210 to $270 \mathrm{~mm}$ for the ulna) in $2-\mathrm{cm}$ increments. There is a single $3.5-\mathrm{mm}$-diameter interlocking hole in the distal end of the radial nail and three such holes in the proximal end of the ulnar nail.

\section{Surgical Technique}

The procedure, performed under tourniquet control, is done with the patient in the supine position on a radiolucent oper-

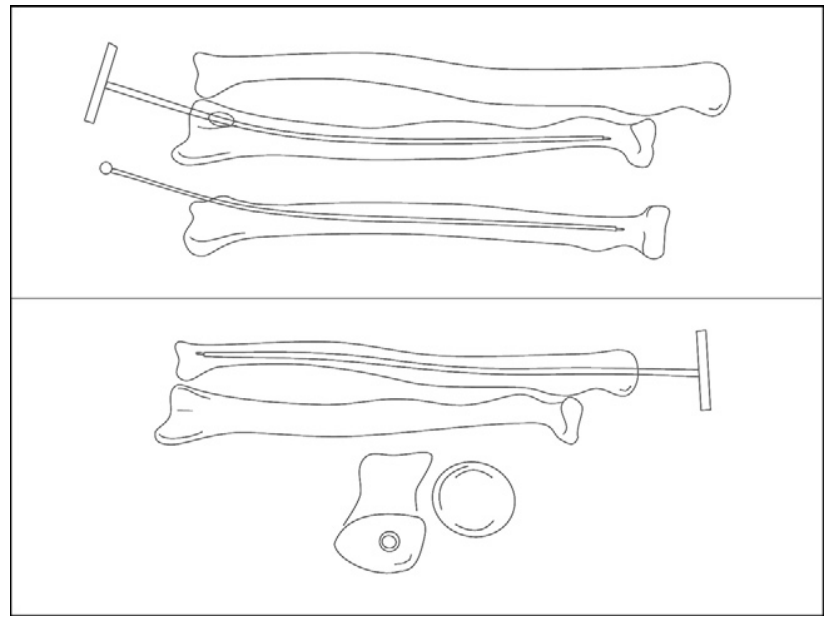

Fig. 2

A radial entry portal is created just ulnar to the Lister tubercle and approximately $5 \mathrm{~mm}$ from the articular surface. The canal is enlarged with use of a T-handle hand reamer (top part of the image). The ulnar entry portal is created at the tip of the olecranon (bottom part of the image). 
The Journal of Bone \& Joint Surgery $\cdot$ JBJS. Org Volume 90-A • Number 9 - September 2008
Interlocking Contoured Intramedullary Nail Fixation for Diaphyseal Forearm Fractures in Adults

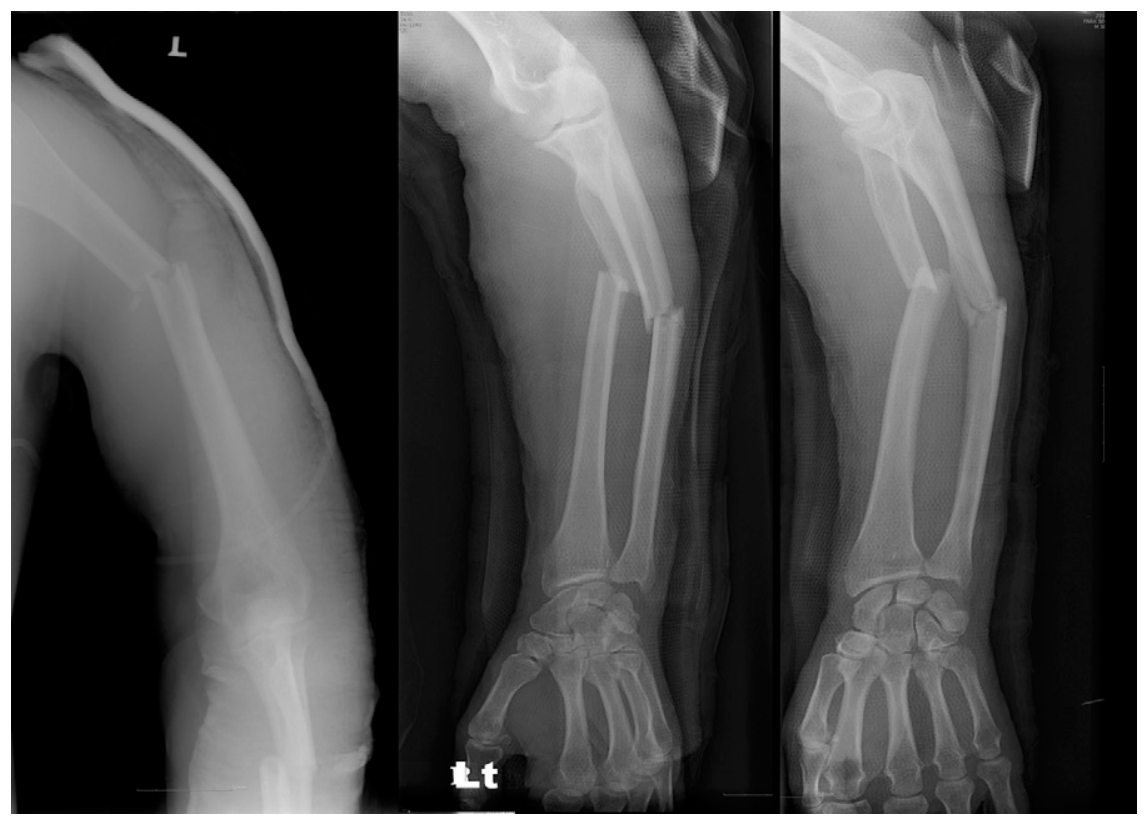

Fig. 3-A

Figs. 3-A and 3-B A fifty-two-year-old man with fractures of the humeral shaft, the proximal onethird of the radial shaft, and the middle one-third of the ulnar shaft. Fig. 3-A Radiographs demonstrating the injuries.

ating table. The nail for a radial fracture is selected on the basis of the length and diameter of the medullary canal as measured on anteroposterior and lateral radiographs of the uninjured forearm. The nail is inserted into the medullary canal through an entry hole created with an awl in the distal end of the radius, just ulnar to the Lister tubercle and approximately $5 \mathrm{~mm}$ from the articular surface. Next, a handheld reamer is inserted to ream the canal and aid in the reduction of the fracture without the use of a guidewire. Two sizes of reamers with diameters of 3.1 and $3.7 \mathrm{~mm}$ are available to enlarge the medullary canal by

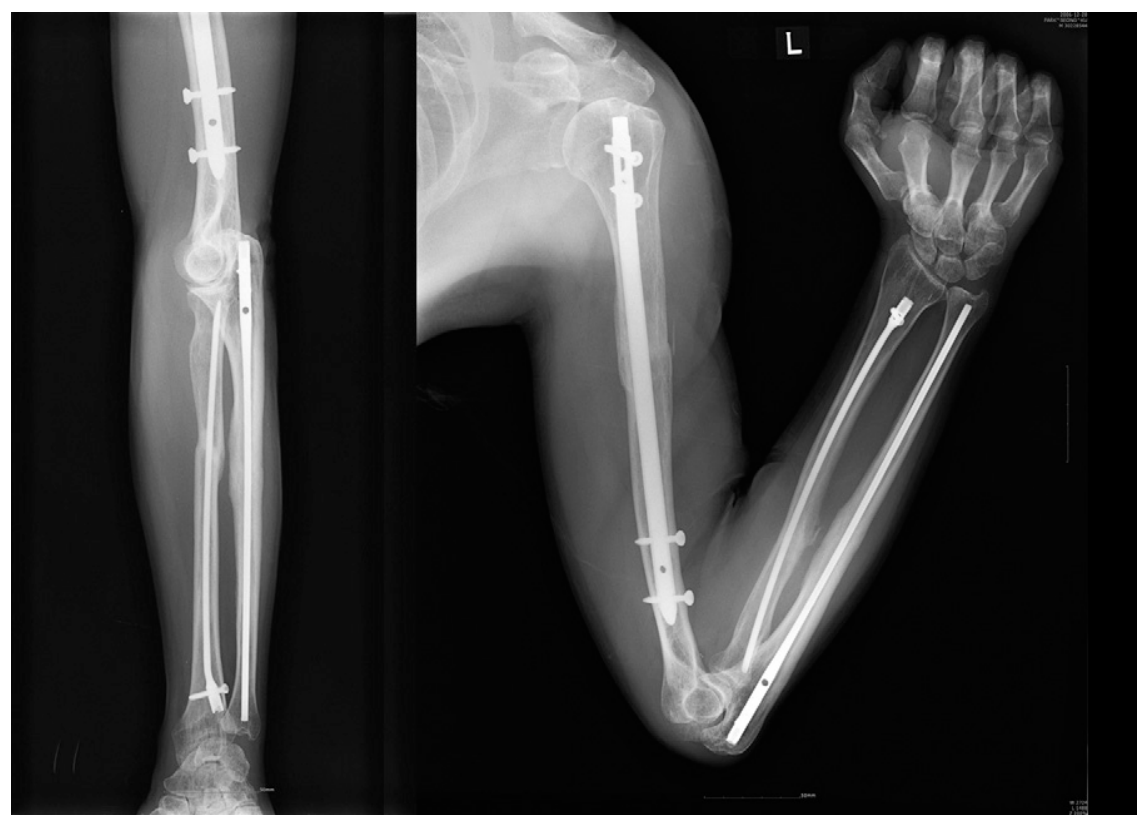

Fig. 3-B

Radiographs made at twelve months postoperatively, demonstrating satisfactory fracture-healing and alignment. 


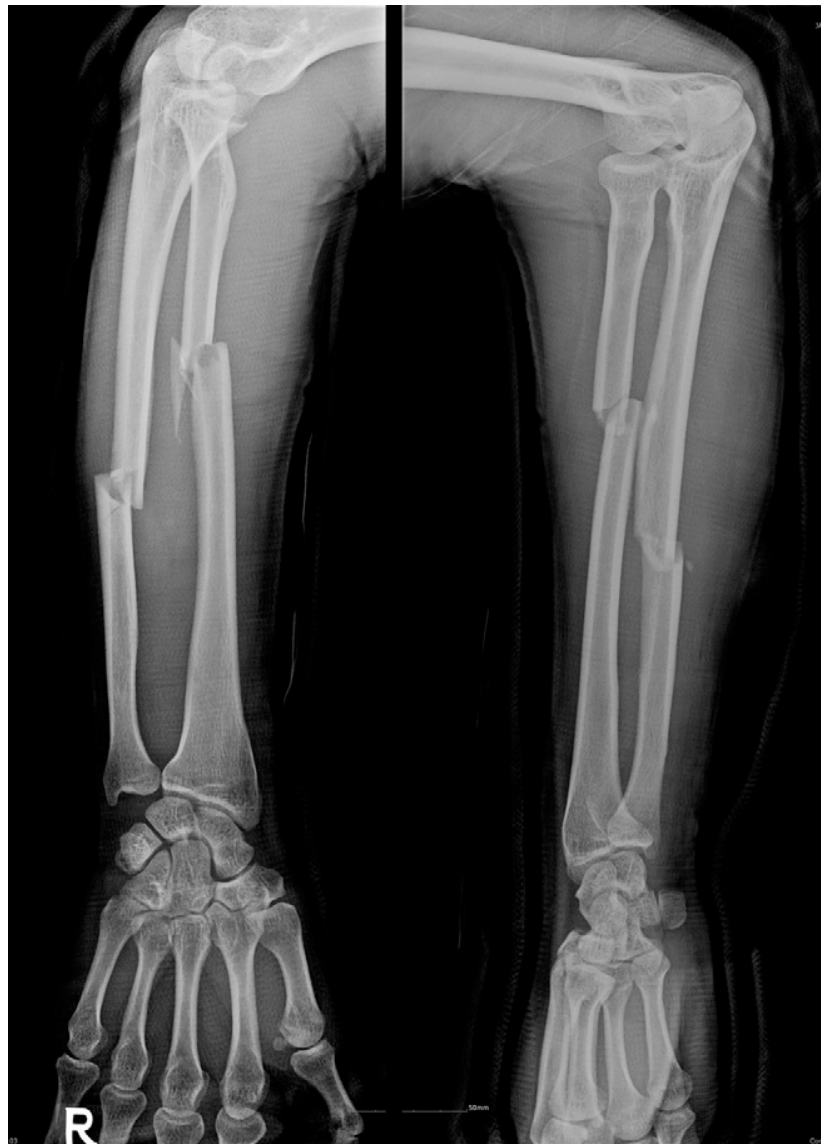

Fig. 4-A

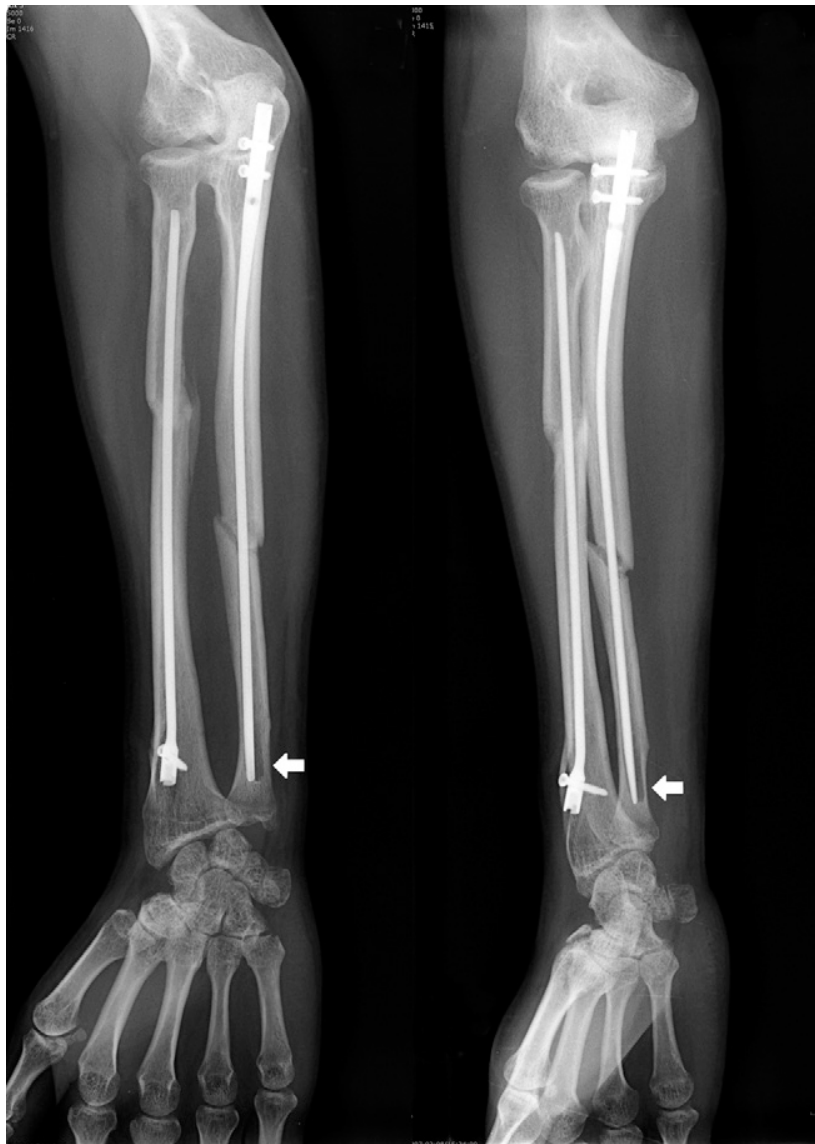

Fig 4-B

Figs. 4-A, 4-B, and 4-C A forty-one-year-old man with a diaphyseal forearm fracture. Fig. 4-A Two radiographs demonstrating the injury. Fig. 4-B Two radiographs made at four months postoperatively. The ulnar fracture did not unite, and the distal end of the ulna was unstable and demonstrated endosteal osteolysis (arrows).

0.1 to $0.6 \mathrm{~mm}$ more than the selected nail diameter in order to prevent incarceration of the nail or distraction of the fracture (Fig. 2). Either the 3.1 or the $3.7-\mathrm{mm}$-diameter reamer is selected on the basis of the preoperative radiographic images of the contralateral, uninjured forearm. There is a possibility of measurement error; therefore, if the $3.1-\mathrm{mm}$ handheld reamer passes relatively easily through the medullary canal, the reaming is performed again with the $3.7-\mathrm{mm}$ reamer in order to allow the use of a $3.6-\mathrm{mm}$ nail instead of a $3.0-\mathrm{mm}$ nail. The chosen reamer is inserted down the length of the radius, and either the nail length is read directly from the reamer shaft or a mark is made on the reamer shaft and the length is measured after it is withdrawn. With use of fluoroscopic guidance, the tip of the selected nail is gently guided past the fracture site and up to the proximal metaphysis. The nail position is assessed fluoroscopically in orthogonal planes to ensure that it has successfully crossed the fracture site and is maintaining a good reduction. The nail is then interlocked with a fully threaded $3.5-\mathrm{mm}$ selftapping screw placed in its trailing end.

A similar procedure is used for an ulnar fracture. Briefly, a longitudinal $1-\mathrm{cm}$-long incision is made at the tip of the olecranon. Dissection is carried down sharply through the subcutaneous tissues and the triceps tendon. Next, a handheld reamer is inserted down the length of the ulna, and either the nail length is read directly from the reamer shaft or a mark is made on the reamer shaft and the length is measured after the reamer is withdrawn. The ulnar nail is inserted through an entry hole created in the proximal part of the olecranon, and interlocking screws are inserted through the proximal end of the nail. There are three interlocking holes in the ulnar nail, and at least two of the three holes should have locking screws.

The success of the fracture reduction and the position of the nail should always be verified fluoroscopically. The wound is closed, and a well-molded long arm cast is applied. To accommodate postoperative swelling, the cast is split longitudinally. At the first postoperative office visit, a hinged elbow brace is applied with the wrist held in neutral. Active rangeof-motion exercises of the elbow are initiated. At six weeks postoperatively, the elbow brace is removed and active forearm supination and pronation exercises are allowed.

\section{Patients and Evaluations}

There were twenty-seven patients, nineteen men and eight women with a mean age of thirty-two years (range, twenty-one 
The Journal of Bone \& Joint Surgery - JBjS. org Volume 90-A · Number 9 - September 2008
Interlocking Contoured Intramedullary Nail Fixation for Diaphyseal Forearm Fractures in Adults

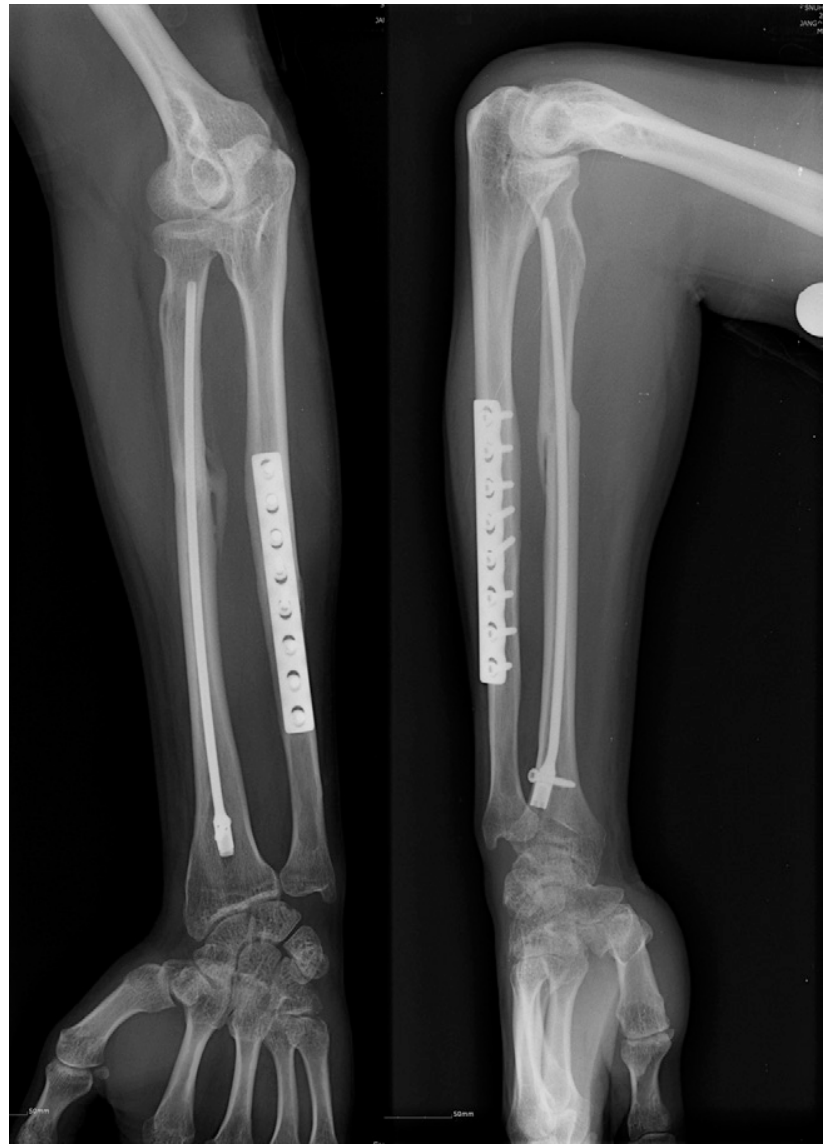

Fig. 4-C

Two radiographs, made at four months following nail removal and plate osteosynthesis combined with an autologous iliac crest bone graft,

showing union of the ulnar fracture.

to fifty-three years). Fifteen right forearms and twelve left forearms were involved. All twenty-seven patients were righthanded. The mechanisms of injury were a motor vehicle accident (ten patients), an industrial accident (eight), a sports injury (five), and a fall (four). According to the AO/ASIF classification $^{21}$, there were twelve type-A (simple) fractures $(32 \%)$, nineteen type-B (wedge) fractures (50\%), and seven type-C (complex) fractures $(18 \%)$. Of the thirty-eight fractures, thirtyone $(82 \%)$ were closed; eight $(26 \%)$ of the closed fractures were associated with only a mild or moderate degree of softtissue damage. The remaining seven fractures (18\%) were open: two were grade I, four were grade II, and one was grade III according to the criteria defined by Gustilo and Anderson ${ }^{19}$. Fifteen of the twenty-seven patients had an isolated forearm injury. The other twelve had multiple injuries: three had a fracture of the ipsilateral humerus (Figs. 3-A and 3-B), three had an ulnar nerve injury, one had a fracture of the ipsilateral humerus and ulnar and radial nerve injuries, two had fractures of the contralateral tibia and ankle, one had a fracture of the ipsilateral fifth metacarpal, and two had a closed head injury.

All seven open fractures were treated with débridement and irrigation, and intramedullary nail fixation was performed on the date of admission. All of the other fractures were stabilized within seven days after the injury. All procedures were performed by one of two surgeons (Y.H.L. and S.K.L.).

Patients were evaluated clinically and radiographically. The follow-up period was a minimum of twelve months (range, twelve to forty-five months; average, seventeen months) for all twenty-seven patients. The results were assessed on the basis of the time to union, functional recovery, complications, and physical capacity. Functional outcomes were assessed with use of the Grace and Eversmann rating system ${ }^{22}$, which is based on fracture union and forearm rotation. Fracture union was judged to have occurred when bridging callus was evident on the anteroposterior, lateral, and oblique radiographs of the forearm. With use of a forearm goniometer, the ranges of pronation and supination were evaluated according to the neutral zero method, with the elbow flexed $90^{\circ}$, and were recorded as a percentage of the range of motion on the contralateral side. When the measurements of pronation-supination of the contralateral forearm were unavailable, it was assumed that the normal arc was $90^{\circ}$ of pronation and $90^{\circ}$ of supination.

The result was rated as excellent when the fracture had united and there was at least $90 \%$ of the normal forearm rotation arc, good when the fracture had united and there was $80 \%$ to $89 \%$ of the rotation arc, acceptable when the fracture had united and there was $60 \%$ to $79 \%$ of normal forearm rotation, and unacceptable when there was a nonunion or $<60 \%$ of normal forearm rotation.

The patient-rated outcome was assessed with use of the Disabilities of the Arm, Shoulder and Hand questionnaire $(\mathrm{DASH})^{23}$. This questionnaire, which is recommended by the Upper Extremity Collaborative Group ${ }^{23}$, allocates scores as percentages. A score of 0 points indicates a perfectly functioning upper extremity, whereas a score of 100 points indicates complete impairment.

\section{Results}

The average operating time was forty-five minutes (range, twenty-five to seventy-eight minutes). Isolated ulnar fractures, isolated radial fractures, and both-bone fractures required a mean operative time of thirty-two minutes (range, twentyfive to thirty-eight minutes), forty-three minutes (range, thirty-five to seventy minutes), and sixty-eight minutes (range, sixty to seventy-eight minutes), respectively. The average fluoroscopy time was seven minutes, although it was thirteen minutes early in our learning curve. No intraoperative complication required a change in the operative technique. The average time to fracture-healing was fourteen weeks (range, nine to thirty-two weeks). There was one nonunion following an open comminuted fracture of the middle third of the ulna (Figs. 4-A, 4-B, and 4-C). In this case, complete radiographic consolidation was achieved sixteen weeks following removal of the nail and application of a plate supplemented with autologous iliac crest bone graft.

The mean pronation and supination were $85^{\circ}$ (range, $82^{\circ}$ to $89^{\circ}$ ) and $87^{\circ}$ (range, $83^{\circ}$ to $90^{\circ}$ ), respectively, following treatment of the isolated ulnar fractures; $84^{\circ}$ (range, $79^{\circ}$ to $87^{\circ}$ ) and $87^{\circ}$ 
The Journal of Bone \& Joint Surgery $\cdot$ JbJs.org Volume 90-A • Number 9 - September 2008
Interlocking Contoured Intramedullary Nail Fixation for Diaphyseal Forearm Fractures in Adults (range, $84^{\circ}$ to $90^{\circ}$ ), respectively, following treatment of the isolated radial fractures; and $79^{\circ}$ (range, $68^{\circ}$ to $84^{\circ}$ ) and $81^{\circ}$ (range, $70^{\circ}$ to $88^{\circ}$ ), respectively, following treatment of the both-bone fractures. All patients had a full range of motion of the wrist and elbow.

Four patients had nerve injuries at the time of presentation: three had an ulnar nerve injury, and one had combined ulnar and radial nerve injuries. All four ulnar nerve injuries were associated with an open fracture and involved complete transection of the ulnar nerve. All four patients had complete recovery of motor function one year after a neurorrhaphy was performed, but two had paresthesias in the ulnar nerve distribution.

One patient with an open fracture had a superficial infection, which resolved after the administration of oral antibiotics. There were no cases of deep infection, radioulnar synostosis between the forearm bones, mechanical irritation by nails or interlocking screws at the distal part of the radius or at the olecranon, compartment syndrome, failure of fixation or breakage of a device (a nail or a locking screw), or refracture. Five nails were removed at the patient's request, at an average of twenty months.

According to the Grace and Eversmann rating system, twenty-two $(81 \%)$ of the twenty-seven forearms had an excellent result, three (11\%) had a good result, and two (8\%) had an acceptable result. One of the two acceptable results was attributed to an ulnar nonunion requiring plate fixation and bone-grafting, and the other was attributed to an ipsilateral humeral fracture as well as ulnar nerve and radial nerve injuries. The DASH scores averaged 15 points (range, 5 to 61 points), and the score was 0 to 19 points (a very good result) for twenty-three forearms $(85 \%)$. Of the four patients with higher DASH scores (range, 22 to 61 points), two had an ipsilateral humeral fracture and one had an ipsilateral humeral fracture and ulnar and radial nerve injuries.

\section{Discussion}

$\mathrm{T}$ his study demonstrated that use of interlocking intramedullary nails for treatment of diaphyseal fractures of the forearm in adults can achieve good results. In 1913, Schöne ${ }^{24}$ first used silver nails for radial and ulnar medullary fixation, and subsequently various nails were developed to stabilize forearm fractures ${ }^{13,14,25-31}$. Moreover, the successful application of closed locking-nail fixation of the femur, tibia, and humerus along with the lack of rotational control of comminuted or segmental fractures offered by interference-fit forearm nails as well as the frustration that surgeons feel about having to apply plates to segmental diaphyseal forearm fractures in the face of poor overlying skin, severe swelling, and refracture rates of $11 \%$ to $20 \%$ after plate removal have led to an interest in locking nailing for forearm fractures ${ }^{32-35}$.

Recently, good results were reported following the treatment of forearm fractures in adults with the ForeSight nail system (Smith and Nephew, Memphis, Tennessee) ${ }^{32}$. However, a careful review of that nail system showed that the nail requires an intraoperative bending procedure to create the anatomic bow of the radius and the serpentine shape of the ulna in each case $\mathrm{c}^{34,35}$. Also, the locking screw placed through the distal part of the ulna can be felt through the skin and can cause mechanical irritation. The early removal of these locking screws to treat loosening of the locking screw and wrist pain has been reported ${ }^{35,36}$. In addition, insertion of the nail and the interlocking screw through the distal part of the ulna, which has a relatively small diameter, may create a weak point around the drill-hole. Moreover, an additional skin incision is required when the locking screw is inserted into the proximal part of the radius, which can cause a posterior interosseous nerve injury ${ }^{34,35}$.

In our series, nails were prebent to facilitate insertion. In addition, the targeted interlocking screw was inserted on only one end of the nail. The other nail end is fluted and has a paddle-blade tip, which is driven into the metaphyseal portion to provide rotational stability. However, since a locking screw is not used at both ends of the nail, this nailing system is not recommended for patients with osteoporosis. The nail for the radius is available in lengths ranging from 190 to $230 \mathrm{~mm}$ in $2-\mathrm{cm}$ increments, and the ulnar nail is available in lengths ranging from 210 to $270 \mathrm{~mm}$ in $2-\mathrm{cm}$ increments. The nail had to be cut by $10 \mathrm{~mm}$ for some of our Asian patients because their forearms were shorter than the shortest nail.

In this series, all fractures (except the open ones) were successfully reduced with use of the closed technique. In one case, the reamer failed to cross the fracture site, and thus the tip of the nail was bent by about $10^{\circ}$ to facilitate its passage.

All but one of the fractures united. The one ulnar nonunion was treated with plate osteosynthesis and an autologous bone graft. Standard surgical treatment of diaphyseal fractures with plate osteosynthesis requires an extensive softtissue dissection, which can compromise the blood supply of the healing fracture ${ }^{2}$. Moreover, atrophy of cortical bone underlying the plate and placement of drill-holes for screws can weaken the forearm bones. These factors contribute to the risk of refracture after plate and screw removal. The advantages of using an intramedullary device is that periosteal stripping is unnecessary, the skin incisions are smaller, and there is less soft-tissue dissection, resulting in preservation of the osseous blood supply, which aids in fracture union ${ }^{37}$. Also, unlike compression plates, intramedullary implants are stress-sharing rather than stress-shielding, which leads to a peripheral periosteal callus that may facilitate stronger fracture union ${ }^{38}$. Despite this abundant callus, a mechanical block to forearm rotation has not been reported, to our knowledge $e^{26,31}$. In our study, there were no cases of radioulnar synostosis.

There was one nonunion, of a grade-IIIA open comminuted fracture with soft-tissue damage and periosteal stripping (Figs. 4-A, 4-B, and 4-C). Although we recommended that the forearm be immobilized in a long arm cast for four weeks after the surgery, the patient prematurely removed the cast. In addition, the nail that we placed should have been $1 \mathrm{~cm}$ longer and we should have inserted it into the end of the distal metaphysis of the ulna to improve stabilization; unfortunately, the only nail available was $2 \mathrm{~cm}$ longer. We speculate that these factors caused the nonunion.

The disadvantage of this procedure is that it requires a longer duration of immobilization (until bridging callus is 
The Journal of Bone \& Joint Surgery Jbjs.org Volume 90-A • Number $9 \cdot$ September 2008
Interlocking Contoured Intramedullary Nail Fixation for Diaphyseal Forearm Fractures in Adults observed) compared with that required following plate osteosynthesis, and the patient must wear a brace. However, since the procedure does not expose the wrist or elbow joint, no patient lost mobility of these joints. Even with the disadvantage of longer immobilization of the forearm, we believe that intramedullary nailing is a reasonable approach that has had good results in selected cases. We think that the utilization of this implant could reduce the current rates of nonunion following use of other nail systems and that the nonunion rate is equivalent to that associated with plate osteosynthesis. The restoration of the radial bow is considered important in terms of reconstituting the normal forearm architecture and restoring forearm rotation and grip strength ${ }^{39}$. In our opinion, this prebent nail cannot restore normal radial bowing accurately in every patient. However, no significant functional impairment will result if forearm angulation is reduced to $\leq 10^{\circ}$ in any plane $(\mathrm{p}>0.01)^{40}$.

We found that fixation of diaphyseal fractures of the forearm in adults with an interlocking contoured intramedullary nail has several merits. It results in a union rate comparable with that following plate fixation. In addition, it requires no periosteal stripping and the incisions are smaller than those required for plate fixation, making the technique particularly appealing when the overlying soft-tissue envelope is tenuous. The disadvantages of this system are that it has relatively limited indications and postoperative immobilization is required until bridging callus is observed at the fracture site. Our experience indicates that the interlocking contoured intramedullary nail system is not superior to plate fixation but can be considered as an alternative to that method for selected diaphyseal fractures of the forearm in adults.

Young Ho Lee, MD

Moon Sang Chung, MD

Goo Hyun Baek, MD

Hyun Sik Gong, MD

Kyung Hwan Kim, MD

Department of Orthopedic Surgery, Seoul National University College of Medicine, 28 Yongon-dong, Chongno-gu, Seoul 110-744, South Korea

Sang Ki Lee, MD

Department of Orthopedic Surgery, Eulji University College of Medicine, 1306 Dunsan-dong, Seo-gu, Daejeon 302-799, South Korea. E-mail address: sklee@eulji.ac.kr

\section{References}

1. Markolf KL, Lamey D, Yang S, Meals R, Hotchkiss R. Radioulnar load-sharing in the forearm. A study in cadavera. J Bone Joint Surg Am. 1998;80:879-88.

2. Ring D, Jupiter JB, Sanders RA, Quintero J, Santoro VM, Ganz R, Marti RK. Complex nonunion of fractures of the femoral shaft treated by wave-plate osteosynthesis. J Bone Joint Surg Br. 1997;79:289-94.

3. Rodriguez-Merchan EC, Gomez-Castresana F. Internal fixation of nonunions. Clin Orthop Relat Res. 2004;419:13-20.

4. Wei SY, Born CT, Abene A, Ong A, Hayda R, DeLong WG Jr. Diaphyseal forearm fractures treated with and without bone graft. J Trauma. 1999;46:1045-8.

5. Wright RR, Schmeling GJ, Schwab JP. The necessity of acute bone grafting in diaphyseal forearm fractures: a retrospective review. J Orthop Trauma. 1997;11:288-94.

6. Labosky DA, Cermak MB, Waggy CA. Forearm fracture plates: to remove or not to remove. J Hand Surg [Am]. 1990;15:294-301.

7. Rumball K, Finnegan M. Refractures after forearm plate removal. J Orthop Trauma. 1990;4:124-9.

8. Hidaka S, Gustilo RB. Refracture of bones of the forearm after plate removal. J Bone Joint Surg Am. 1984;66:1241-3.

9. Rosson JW, Shearer JR. Refracture after the removal of plate from the forearm. An avoidable complication. J Bone Joint Surg Br. 1991;73:415-7.

10. Bednar DA, Grandwilewski W. Complications of forearm-plate removal. Can J Surg. 1992;35:428-31.

11. Hertel R, Pisan M, Lambert S, Ballmer FT. Plate osteosynthesis of diaphyseal fractures of the radius and ulna. Injury. 1996;27:545-8.

12. Chapman MW, Gordon JE, Zissimos AG. Compression-plate fixation of acute fractures of the diaphyses of the radius and ulna. J Bone Joint Surg Am. 1989;71:159-69.

13. Rush LV, Rush HL. A technique for longitudinal pin fixation of certain fractures of the ulna and of the femur. J Bone Joint Surg Am. 1939;21:619-26.

14. Sage FP. Medullary fixation of fractures of the forearm: a study of the medullary canal of the radius and a report of fifty fractures of the radius treated with a prebent triangular nail. J Bone Joint Surg Am. 1959;41:1489-525.

15. Brumback RJ, Virkus WW. Intramedullary nailing of the femur: reamed versus nonreamed. J Am Acad Orthop Surg. 2000;8:83-90.

16. Finkemeier CG, Schmidt AH, Kyle RF, Templeman DC, Varecka TF. A prospective, randomized study of intramedullary nails inserted with and without reaming for the treatment of open and closed fractures of the tibial shaft. J Orthop Trauma. 2000;14:187-93.

17. Stannard JP, Harris HW, McGwin G Jr, Volgas DA, Alonso JE. Intramedullary nailing of humeral shaft fractures with a locking flexible nail. J Bone Joint Surg Am. 2003;85:2103-10.

18. McAuliffe JA. Forearm fixation. Hand Clin. 1997;13:689-701.

19. Gustilo RB, Anderson JT. Prevention of infection in the treatment of one thousand and twenty-five open fractures of long bones: retrospective and prospective analyses. J Bone Joint Surg Am. 1976;58:453-8.

20. Gustilo RB, Mendoza RM, Williams DN. Problems in the management of type II (severe) open fractures: a new classification of type III open fractures. J Trauma. 1984;24:742-6.

21. Müller ME, Allgower $M$, Schneider $R$, Willenegger $H$, editors. Manual of internal fixation: techniques recommended by the AO-ASIF group. 3rd ed. Berlin: Springer; 1991.

22. Grace TG, Eversmann WW Jr. Forearm fractures: treatment by rigid fixation with early motion. J Bone Joint Surg Am. 1980;62:433-8.

23. Hudak PL, Amadio PC, Bombardier C. Development of an upper extremity outcome measure: the DASH (Disabilities of the Arm, Shoulder and Hand). The Upper Extremity Collaborative Group (UECG). Am J Ind Med. 1996;29:602-8. Erratum in: Am J Ind Med. 1996;30:372.

24. Schöne G. Zur behandlung von vorderarmfrakturen mit bolzung. Münch Med Wochenschr. 1913;60:2327-8.

25. Cole JD. SST Small Bone Locking Nail-forearm nail: surgical technique. Warsaw, IN: Biomet; 1998.

26. Crenshaw AH, Zinar DM, Pickering RM. Intramedullary nailing of forearm fractures. Instr Course Lect. 2002;51:279-89.

27. De Pedro JA, Garcia-Navarrete F, Garcia De Lucas F, Otero R, Otero A, Lopez-Duran Stern L. Internal fixation of ulnar fractures by locking nail. Clin Orthop Relat Res. 1992:283:81-5.

28. Hall RH, Bugg El, Vitolo RE. Intramedullary fixation of fractures of the forearm. South Med J. 1952;45:814-8.

29. Marek FM. Axial fixation of forearm fractures. J Bone Joint Surg Am. 1961;43:1099-114.

30. Street DM. Medullary nailing of forearm fractures. J Bone Joint Surg Am. 1957;39:715. 


\section{8}

The Journal of Bone \& Joint Surgery · Jbjs.org Volume 90-A • Number 9 - September 2008

31. Zinar DM, Street $D$, Wolgin $M$. Intramedullary nailing of the forearm. In: Browner BD, editor. The science and practice of intramedullary nailing. 2nd ed. Baltimore: Williams and Wilkins; 1996. p 265-86.

32. Crenshaw AH Jr. Fractures of shoulder girdle, arm, and forearm. In: Canale ST, Beaty JH, editors. Campbell's operative orthopaedics. 11th ed. St. Louis: Mosby; 2008. p 3431-41.

33. Jones DJ, Henley MB, Schemitsch EH, Tencer AF. A biomechanical comparison of two methods of fixation of fractures of the forearm. J Orthop Trauma. 1995;9:198-206.

34. Gao H, Luo CF, Zhang CQ, Shi HP, Fan CY, Zen BF. Internal fixation of diaphyseal fractures of the forearm by interlocking intramedullary nail: shortterm results in eighteen patients. J Orthop Trauma. 2005;19:384-91.

35. Weckbach A, Blattert TR, Weisser Ch. Interlocking nailing of forearm fractures. Arch Orthop Trauma Surg. 2006;126:309-15.
Interlocking Contoured Intramedullary Nail Fixation for Diaphyseal Forearm Fractures in Adults

36. Hong G, Cong-Feng L, Hui-Peng S, Cun-Yi F, Bing-Fang Z. Treatment of diaphyseal forearm nonunions with interlocking intramedullary nails. Clin Orthop Relat Res. 2006;450:186-92.

37. Moerman J, Lenaert A, De Coninck D, Haeck L, Verbeke S, Uyttendaele D, Verdonk R. Intramedullary fixation of forearm fractures in adults. Acta Orthop Belg. 1996;62:34-40.

38. Rand JA, An KN, Chao EY, Kelly PJ. A comparison of the effect of open intramedullary nailing and compression-plate fixation on fracture-site blood flow and fracture union. J Bone Joint Surg Am. 1981;63:427-42.

39. Schemitsch EH, Richards RR. The effect of malunion on functional outcome after plate fixation of fractures of both bones of the forearm in adults. J Bone Joint Surg Am. 1992;74:1068-78.

40. Matthews LS, Kaufer H, Garver DF, Sonstegard DA. The effect on supinationpronation of angular malalignment of fractures of both bones of the forearm. J Bone Joint Surg Am. 1982;64:14-7. 